\title{
COMMITMENT AND MONOPOLY PRICING IN DURABLE GOODS MODELS
}

\author{
Valerie Y. SUSLOW* \\ University of Michigan, Ann Arbor, MI 48109. USA
}

Final version received August 1986

\begin{abstract}
This article investigates the issue of commitment by a durable goods monopolist. Two models of the interaction between durability, recycling, and market power are compared. The two differ according to the ability of the seller to credibly commit to a given sales strategy. This article takes the standard durable goods monopoly model, extends it to allow for depreciation, and compares the monopoly markup with Swan's predicted markup for a recycled good. The difference between the two medels is shown to reduce to a single parameter in the markup equation.
\end{abstract}

\section{Introduction}

The existing literature on the relationship between durability, recycling, and market power has taken two distinct approaches. Coase (1972), Jtokey (1981) and Bulow (1982) model a durable goods monopoly seller who c nnot commit to a given sales strategy. Their emphasis has been on character zing the equilibrium price path through time. Swan (1980) focuses instead o the effec of secondhand markets on monopoly rents. ${ }^{1}$ His model allow for commitment and the analysis is restricted to the steady state.

This article brings these two approaches together in a simple way. Fir ; $t$, I extend Bulow's two-period discrete-time model to a finite period model that allows for depreciation. ${ }^{2}$ A steady state can then be derived, restricting the difference between the two models to the commitment assumption. The results show that the notion of commitment (or lack of cummitment) $c \varepsilon n$ be

*This paper is adapted from my Ph.D. dissertation. I am indebted to Tim Bresnahan for detailed comments on previous drafts of the paper. I retain responsibility for all errors.

${ }^{1}$ See also Sieper and Swan (1973), Gaskins (1974) and Schmalensee (1974).

${ }^{2}$ This paper is based on my thesis, Suslow (1984). In a recent article, Bond and Samuelson (1984) extend Stokey's (1981) model to allow for depreciation and capacity constraints. They focus on the stock of the good with replacement sales allowed, and how this stock relates to the competitive level. My model, which also allows for depreciation, yields "ery similar results. I

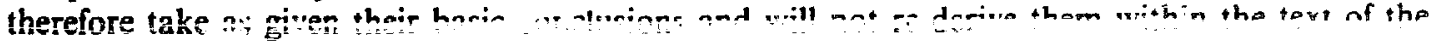
paper. 
parameterized in a straightforward manner. The paper concludes by showing how the monopoly markup formulas implied by the two approaches differ in an empirically testable way.

\section{Durable goods monopoly with depreciation}

According to conventional analysis, a producer who rents a durable good will maximize profits by setting marginal revenue from the stock demand curve equal to marginal cost. Each period the static monopoly quantity is rented at the static monopoly rental price. Can a seller achieve this level of profits? Yes, if it can commit to producing only the monopoly quantity in the iirst period and zero units thereafter. Consumers are charged a sales price the first period that reflects the present discounted value of the stream of equilibrium prices set by the renter. This price will clear the market. Perfect foresight guaiantees that consumers are willing to pay a sales price today that represents the present discounted value of all future service flow values (rental prices) of the durable good.

If the monopolist has no means of credibly commiting to a predetermined production path an incentives problem arises. Reducing the price in order to increase sales imposes a capital loss not on the seller, but on its previous customers. The fact that this capital loss is not internalized creates an incentive to continue selling as long as positive incremental profits can be made. If buyers are aware of this incentive, the firm cannot credibly commit to a strategy which professes to restrict output.

The key to solving the muiti-period problem in the non-commitment case lies in enforcing the constraint imposed by a perfect equilibrium, which calls for strategies that are optimal at any point in time. In the second to last period the consumers can calculate the profit maximizing strategy of the monopolist, given the total outstanding stock. Thus, they can formulate a rule for the final, period $T$, price as a function of the penultimate period price (since there are no commitment issues in period $T$ ). This rule becomes a constraint to be satisfied for the monopolist maximizing profits from period $T-1$ to period $T$. By repeating this process, consumers can arrive at a rule relating price in period $T-2$ to price in $T-1$, given the price rule relating period $T-1$ to $T$, and so on. The monopolist looking at the problem from any time $t$ forward is therefore faced by a set of constraints from time $t+1$ to $T$.

Let $Q_{1}$ be the end-of-period cumulative stoc'.. There is a discount factor of $\delta$, and a constant depreciation rate $\gamma$. Then $q_{t}=Q_{t}-(1-\gamma) Q_{t-1}$ defines the sales flow in period $t$. Also, let $P_{R i}=f\left(Q_{t}\right)$ be the known rental demand curve. The beginning-of-period sales price, $P_{S t}$, is equal to the discounted value of the future implicit rental prices (for that fraction of the goods that has not depreriated). or 


$$
P_{S t}=\sum_{t=\mathrm{r}}^{T}[\delta(1-i)]^{t-?} P_{R t}
$$

Perfect foresight over $Q$, and knowledge of the demand curve on the part of consumers enforces condition (1).

Marginal cost is assumed to be zero without loss of generality. The monopolist's objective function at any time $\tau$ can be written as

$$
\Gamma^{t}=\sum_{r=\tau}^{T} \delta^{1-\tau} P_{S r} q_{r}
$$

Using (1) to make the transformation from flow variables to stock variables yields

$$
\Pi^{r}=\sum_{t=\tau}^{T} \delta^{1-\tau}\left\{\sum_{v=\imath}^{T}[\delta(1-\gamma)]^{r \cdot t} P_{R v}\right\}\left[Q_{t}-(1-\gamma) Q_{t-1}\right]
$$

Upon manipulation this reduces to

$$
\Pi^{\mathfrak{r}}=\sum_{t=\tau}^{T} \delta^{t-\tau} P_{R}\left[Q_{t}-(1-\gamma)^{t-\tau+1} Q_{r-1}\right]
$$

The monopolist's problem is that of choosing a rental price at any point in time subject to the (perfectness) constraint that price must be set optimally in all future periods. The set of all such prices $\left\{P_{R i}^{*}\right\}$ constitutes an equilibrium strategy. For ariy particular $\tau$ the maximization problem is thus:

$$
\begin{aligned}
& \max _{P_{R \tau}} \Pi^{\tau}=\sum_{i=\tau}^{T} \delta^{t-\tau} P_{R t}\left[Q_{t}-(1-\gamma)^{t-\tau+1} Q_{\tau-1}\right], \\
& \text { s.t. } \quad{ }_{k}=\underset{F_{R k}}{\operatorname{argmax}} \Pi^{k} \quad \forall k>\tau,
\end{aligned}
$$

whe $\cdot \Pi^{k}$ is defined according to (3). Subject to (5), the solution of the noncommitment problem involves solving $T$ one-period maximizations, starting from perind $T$ and working backwards. The monopolist chooses $P_{R t}$, for any $\tau$, knowing that $P_{R k}$. for $k>\tau$ will be chosen in a similar manner when period $k$ is reached. ${ }^{3}$

If is important to emphasize that (4) is ihe seller's objective function

${ }^{3}$ The natural value function one might think of with cumulative stock as the state variable does not satisfy the requirements for a dynamic programming iolution. The difficulty lies in the fact that while current stock is a function of past output, current sales price is a function of al! future rerital prices which are in turn a function of future output 
written equivalently in terms of rental price and total stock. The transformation is made to make the problem more tractable. Substituting the rational expectations assumption, eq. (1), into the objective function, rather than imposing it as an outside constrairt, allows rental price to become the natural choice variable. The mathematics of the multi-period model then becomes much more direct.

Solving (4) for eact: future period yields a function of the general form

$$
P_{R k}^{*}=g_{k}\left(P_{k i k-1} \mid Q_{k-1}\right) \text {. }
$$

The function $g_{k}$ relates last period's price to this period's price given an arbitrary stock last period. Consumers use $g_{k}$ to 'predict' (with perfect foresight) any future capital losses. In turn, this prediction determines the price they are willing to pay in the current period. In this manner, $g_{k}$ becomes a constraint on the monopolist's behavior. Thus, eq. (6) describes an implicit price updating rule,

$$
\frac{\mathrm{d} P_{R k}^{*}}{\mathrm{~d} P_{R k-1}}=g_{k}^{\prime}\left(P_{R k-1} \mid Q_{k-1}\right)
$$

The price updating rule shows that the prices set by the monopolist are linked through time. This link is the key to differentiating between commitment and non-commitment models.

Using (7) one can now obtain the first-order condition for maximizing (4) subject to (5),

$$
\begin{aligned}
P_{R t} & \frac{\partial Q_{\tau}}{\partial P_{R t}}+\left(Q_{\tau}-(1-\gamma) Q_{t-1}\right)= \\
& -\sum_{t=\tau+1}^{T} \delta^{t-\tau}\left(\prod_{k=\tau+1}^{t} g_{k}^{\prime}\right)\left[P_{R t} \frac{\partial Q_{t}}{\partial P_{R t}}+\left(Q_{t}-(1-\gamma)^{t-\tau+1} Q_{\tau-1}\right)\right] .
\end{aligned}
$$

According to (8), profits are maximized given the outstanding stock by increasing the period $t$ price until that point where the current residual marginal revenue loss [the left hand side of (8)] is equal to the discounted value of the residual marginal revenue gains from having sold less stock at time $\tau$ [the right hand side of (8)].

For a general demand function, Theorem 1 of the appendix shows that the monpolist makes positive sales in every period. The final level of the stock, however, is lower than if $\gamma=0$. The intuition behind this result is straightforward. Consumers are willing to pay a higher price today for a fixed amount of the durable good becalse they anticipate a smaller increase in 
supply in later periods. The product being sold now yields its services over a shorier period of time. A portion of the firm's monopoly power should therefore be retained.

Lemma 2 of the appendix derives the properties of the price updating rule. Optimal prices decline at an increasing rate over time. For the case of linear demand, this rate of decline is bounded: $g_{1}^{\prime}$ anproaches a value of one as $T$ approaches infinity, and $g_{T}^{\prime}=(1-\gamma) / 2$. Note that $g_{T}^{\prime}=(1-\gamma) / 2$ describes the optimal price updating rule for a monopolist free from intertemporal complications on the demand side. A larger value of $g^{\prime}$ exposes the fact that present and future demand are linked.

\section{Comparison of monopoly markup formulas}

The next step is to compare the steady-state markup formula for the monopolist under the conditions imposed by the durable goods monopoly model and by the simplest recycling model used in Swan $(1980),{ }^{4}$ where scrap is discarded by users. The methodology followed in the durable goods monopoly model is to maximize profits first, and then pass to the steady state. $^{5}$ Depreciation of the stock is replaced each period in the steady state. This requires substituting the condition

$$
Q_{\tau}=Q_{\tau+1}=Q_{\tau+2}=\cdots
$$

into the first-order condition, eq. (8). Using the fact that $g_{t}^{\prime}$ is a constant over $t$ in the steady state, an expression for the implicit monopoly price in terms of $g^{\prime}$ and the rental demand elasticity $\eta$ is derived (see the appendix),

$$
Q\left[1+\left(\frac{1-\delta(1-\gamma) g^{\prime}}{\gamma}\right) \eta\right]=0
$$

Swan solves by finding an expression for steady-state sales and then maximizing profits. To derive steady state $q$ multiply the relationship $q_{t}=Q_{\text {t }}$ $-(1-\gamma) Q_{t-1}$ by $\delta^{t}$ and sum,

${ }^{4}$ I do not use a specific model of Swan's, but compare the methodology he uses with the durable goods monopoly approach. However, Swan's 'boy scouts' model comes very close to the model used here. In this model a scrap variable is included, but scrap is discarded by users umu scavenged by boy scouts who place a lnw value on their time.

${ }^{5}$ The steady state for the monopolist who can precommit involves producing the static equilibrium monopoly output in the first period and subsequently producing only to replace depreciation. 


$$
\begin{aligned}
\sum_{t=0}^{\infty} \delta^{t} q_{t} & =\sum_{t=0}^{\infty} \delta^{t} Q_{t}-\sum_{t=0}^{\infty} \delta^{t}(1-\gamma) Q_{t-1} \\
& =\sum_{-=1}^{\infty} \delta^{t} \Omega_{t}-\sum_{t=-1}^{\infty} \delta^{t+1}(1-\gamma) Q_{t} \\
& =\lambda_{t}-\delta \sum_{t=0}^{\infty} \delta^{2}(1-\gamma) Q_{t}-(1-\gamma) Q_{-1},
\end{aligned}
$$

where $Q_{-1}$ is the inivis condition.

Using the series summation formula,

$$
\begin{aligned}
& q\left(\frac{1}{1-\delta}\right)=Q\left(\frac{1}{1-\delta}\right)-\delta(1-\gamma) Q\left(\frac{1}{1-\delta}\right)-(1-\gamma) Q_{-1} \\
& \Rightarrow q=Q-\delta(1-\gamma) Q-(1-\delta)(1-\gamma) Q_{-1} .
\end{aligned}
$$

in the steady state,

$$
P_{S \mathrm{r}}=P_{R} \sum_{t=\mathrm{r}}^{\infty} \delta^{t-\tau}=P_{R}\left(\frac{1}{1-\delta}\right)
$$

Therefore, steady-state profits are

$$
\begin{aligned}
\Pi=P_{S} \Psi= & \frac{1}{1-\delta} P_{R}\left[Q\left(P_{R}\right)-\delta(1-\gamma) Q\left(P_{R}\right)-(1-\delta)(1-\gamma) Q_{-1}\right] \\
\Rightarrow & \frac{\partial \Pi}{\partial P_{R}}=\frac{1}{1-\delta}\left[\left(Q\left(P_{R}\right)-\delta(1-\gamma) Q\left(P_{R}\right)\right.\right. \\
& \left.\quad-(1-\delta)(1-\gamma) Q_{-1}-P_{R}\left(\frac{\partial Q}{\partial P_{R}}-\delta(1-\gamma) \frac{\partial Q}{\partial P_{R}}\right)\right]=0 .
\end{aligned}
$$

But in the steady state the formula for $q$ collapses to $q=\gamma Q$, so that the firstorder condition becomes

$$
\gamma Q+P_{R} \frac{\partial Q}{\partial P_{R}}(1-\delta(1-\gamma))=0
$$

This yields a final monopoly pricing formula using Swan's approach of

$$
Q\left[1+\left(\frac{1-\delta(1-\gamma)}{\gamma}\right) \eta\right]=0
$$


Comparing (9) and (10) yields the main result: the two markup expressions are identical aside from the appearance of the price updating rule, $g^{\prime}$. The absence of a link between prices over time in eq. (10) shows that Swan's solution concept allows the firm to commit to a steady-state quantity.

Given that $g^{\prime}$ must be less than one, eqs. (9) and (10) imply that the vaiue of the rental demand price elasticity must be greater in (10). One can infer from this that the level of the steady-state stock is higher without commitment. Thus, while there is only one price charged in the steady state, regardless of the commitment assumption, it is the threat of a decrease in price that causes the result in the durable goods monopoly model to differ in a significant way. This theoretical result opens up the possibility of empirically distinguishing between commitment and non-commitment behavior.

\section{Concluding remarks}

In empirical oligopoly models, it is the convention to have those parameters, $\lambda$, which index the oligopoly solution concept, enter an equation of the form $M R(\lambda)=M C^{6}$. The degree to which durability affects pricing is also an empirical issus. In the case with intertemporally complicated demand, marginal revenue will be a function of both current and future sales. In an appropriately specified model it should be possible to identify the parameter we have called the price updating rule. This parameter would reflect a link between current and future marginal revenue. From these theoretical underpinnings future work will attempt to construct empirical tests of the commitment issues raised in the durable goods mosopoly literature.

\section{Appendix: Equilibrium properties with depreciation and derivation of steady-state markwp}

Totally differentiate eq. (8) to find the optimal price updating rule,

$$
g_{\tau}^{\prime}=\frac{\frac{\partial Q_{\tau-1}}{\partial P_{R \tau}-1}\left[(1-\gamma)+\sum_{t=\tau+1}^{T} \delta^{t-\tau} m_{\tau+1}^{t}(1-\gamma)^{t-\tau+1}\right]}{\frac{\partial M R_{\tau}}{\partial P_{R t}}+\sum_{t=\tau+1}^{T} \delta^{t-\tau}\left[m_{\tau+1}^{\prime \prime}\left(M R_{t}-\left(1-\eta^{\prime}\right)^{t+\tau+1} Q_{\tau-1}\right)+\left(m_{\tau}^{t}+1\right)^{2} \frac{\partial M R_{t}}{\partial P_{R t}}\right]},
$$

where

$$
m_{\tau+1}^{t}=\prod_{k=\tau}^{t} g_{k}^{\prime} \text { and } m_{\tau+1}^{\prime \prime}=\prod_{k=1}^{t} g_{k}^{\prime \prime}
$$

6Se, for example, Bresnahan (1981), Gollop and Roberts (1979) and Iwata (1974). 
Lemma 1. $g_{k}^{\prime}>0$.

Proof. Proof by induction. Assume $g_{k}^{\prime}>0$ for all $k>\tau$ and show $g_{\tau}^{\prime}>0$.

The denominator of (A.1) is negative by the second-order conditic The assumption $g_{k}^{\prime}>0$ implies $m_{\tau+1}^{t}>0$, and with downward sloping der. c. we have $g_{r}^{\prime}>0$.

The irduction begins by showing $g_{T}^{\prime}>0$. From (A.1),

$$
g_{T}^{\prime}=\frac{(1-\gamma)\left(\partial Q_{T-1} / \partial P_{R T-1}\right)}{\partial M R_{T} / \partial P_{R T}}>0
$$

Theorem 1. In equilibrium the monopolist's strategy satisfies $q_{t}>0$. That is, there exists no time $\tau$ such that $Q_{\tau}=(1-\gamma)^{t-\tau+1} Q_{\tau-1} \forall t \geqq \tau$.

Proof. If there does exist such a $\tau$ then eq. (8) in the text $\mathrm{b} s$ somes

$$
P_{R} \frac{\partial Q_{\tau}}{\partial P_{R}}=-\sum_{t=\tau+1}^{T} \delta^{t-\tau}\left(\prod_{k=\tau+1}^{t} g_{k}^{\prime}\right) P_{R} \frac{\partial Q_{t}}{\partial P_{R}}
$$

which is a contradiction unless $P_{R}=0$.

Lemma 2. For the case of $P_{R t}=f\left(Q_{t}\right)$ a linear function, $(1-\gamma) / 2 \leqq g_{k}^{\prime}<1$. The equality $g_{k}^{\prime}=(1-\gamma) / 2$ holds only for $k=T$ and $g_{1}^{\prime}=1$ holds as $T$ approaches infinity.

Proof. For the linear case (A.1) is

$$
g_{t}^{\prime}=\frac{1-\gamma+\sum_{t=\tau+1}^{T} \delta^{t-\tau}(1-\gamma)^{t-\tau+1} \prod_{k=\tau+1}^{t} g_{k}^{\prime}}{2+2 \sum_{t=\tau+1}^{T} \delta^{t-\tau} \prod_{k=\tau+1}^{t}\left(g_{k}^{\prime}\right)^{2}} .
$$

For $\tau=T$ this reduces to $\left.g_{T}^{\prime}(1-\gamma) / 2\right)$.

For $\tau<T$ expand the formula

$$
\begin{aligned}
g_{\tau}^{\prime}= & \left((1-\gamma)+\left[\delta(1-\gamma)^{2} g_{\tau+1}^{\prime}+\delta^{2}(1-\gamma)^{3} g_{\tau+1}^{\prime} g_{\tau+2}^{\prime}\right]\right) / \xi \\
& +\left(\cdots+\delta^{T-\tau}(1-\gamma)^{r-\tau+1} g_{\tau+1}^{\prime} \ldots g_{\tau}^{\prime}\right) / \xi,
\end{aligned}
$$

where $\xi=2+\left[2 \delta g_{\tau}^{\prime 2}+2 \delta^{2} g_{\tau+1}^{\prime 2} g_{\tau+2}^{\prime 2}+\cdots+2 \delta^{T-\tau} g_{\tau+1}^{\prime 2} g_{\tau+2}^{\prime 2} \ldots g_{T}^{\prime 2}\right]$. One can show $g_{\tau}^{\prime}<1$ by subtracting the two terms in square brackets and arriving at 
the following equation:

$$
\delta g_{\tau+1}^{\prime}\left[g_{\mathfrak{r}+1}^{\prime} y-(1-\gamma) x\right]
$$

where $g_{\tau+1}^{\prime}$ is of the form $g_{\tau+1}^{\prime}=x / y$.

Thus, $g_{r}^{\prime}<1$ is equivalent to stating

$$
\begin{gathered}
2-(1-\gamma)+\delta g_{\tau}^{\prime}+1(\gamma x)>0, \quad \text { from (A.2) and (A.3) } \\
\Leftrightarrow 1+\gamma+\delta \gamma x g_{\tau+1}^{\prime}>0,
\end{gathered}
$$

which must hold since $g_{\tau+1}^{\prime}>0$ and $x>0$.

\section{Steady-state markup}

To find the steady-state monopoly markup substitute $Q_{t}=Q_{t}=\cdots=Q$ into (8) and factor,

$$
\begin{aligned}
& \left(P_{R} \frac{\partial Q}{\partial P_{R}}+Q\right)\left(1+\sum_{t=\tau+1}^{\infty} \delta^{t-\tau} m_{\tau+1}^{t}\right) \\
& -((1-\gamma) Q)\left(1+\sum_{t=\tau+1}^{\infty} \delta^{t-\tau} m_{\tau+1}^{t}(1-\gamma)^{t-\tau}\right)=0 \\
& \Leftrightarrow\left(P_{R} \frac{\partial Q}{\partial P_{R}}+Q\right)\left(\sum_{t=\tau}^{\infty} \delta^{t-\tau} m_{t+1}^{t}\right)-(1-\gamma) Q\left(\sum_{t=\tau}^{\infty} \delta^{t-\tau} m_{\tau}^{t}+1(1-\gamma)^{t-\tau}\right)=0 .
\end{aligned}
$$

In the steady state the price updating rule is a constant $g^{\prime}$ for all $k$, so that

$$
\begin{aligned}
& P_{R} \frac{\partial Q}{\partial P_{R}}\left(\frac{1}{1-\delta g^{\prime}}\right)+Q\left(\frac{1}{1-\delta g^{\prime}}\right)-(1-\gamma) Q\left(\frac{1}{1-\delta(1-\gamma) g^{\prime}}\right)=0 \\
& \Leftrightarrow P_{R} \frac{\partial Q}{\partial P_{R}}+Q\left(\frac{\gamma}{1-\delta(1-\gamma) g^{\prime}}\right)=0
\end{aligned}
$$

or

$$
Q\left[1+\left(\frac{1-\delta(1-\gamma) g^{\prime}}{\gamma}\right) \eta\right]=0
$$

which is eq. (9) in the text. 


\section{Referencer}

Bond, E.W. and L. Samuelson 1984, Durable good monopolies with rational expectations and replacement sales, Rand Journal of Economics 15, Autumn, 336-345.

Bresnahan, T., 1981, Competition and collusion in the American automobile industry: The 1955 price war, Research Papers in Economics of Factor Markets, no. 2 (Stanford University, Palo Alto, CA).

Bulow, J.I., 1982, Durable goods monopolists, Journal of Political Economy 90, no. 2, 314-332.

Coase, R.H., 1972, Durability and monopoly, Journal of Law and Economics 15, Aprii, 143-149.

Gaskins, D., 1974, Alcoa revisited: The welfare implications of a secondhand market, Journal of Economic Theory 7, March, 254-271.

Gollop, F. and M. Roberts, 1979, Firm interdependence in oligopolistic markets, Journal of Econometrics 10, 313-331.

Iwata, G., 1974, Measurement of conjectural variations and oligopoly, Econometrica 42, Sept., 947-966.

Kydland, F.E. and E.C. Prescott, 1977, Rules rather than discretion: The inconsistency of oftimal plans, Journal of Political Economy 85, June, 473-491.

Schmalensee. R., 1974, Market structure, durability, and maintenance effort, Review of Economic Studies 40, July, 333-351.

Sieper, E. and P.L. Swan, 1973, Monopoly and competition in the market for curable goods, Review of Economic Studies 40, July, 333-351.

Spence, M. and D. Starrett, 1975, Most rapid approach paths in accumulation problems, International Economic Review 16, June, 388-403.

Stokey, N.L., 1981, Rational expectations and durable goods pricing, Bell Journal of Economics 12 , Spring, 112-128.

Suslow, V., 1984, Monopoly pricing with intertemporal complications, unpublished Ph.D. dissertation (Stanford University, Stanford, CA).

Swan, P.L., 1980, Alcoa: The influence of recycling on monopoly power, Journal of Political Economy 88, Feb., 76-99. 